\title{
A controlled trial of a dissonance-based eating disorders prevention program with Brazilian girls
}

\author{
Ana Carolina Soares Amaral ${ }^{1 *}$, Eric Stice ${ }^{2}$ and Maria Elisa Caputo Ferreira ${ }^{3}$
}

\begin{abstract}
Background: Given that most young women with eating disorders do not receive treatment, implementing effective prevention programs is a public health priority. The Body Project is a group-based eating disorder prevention program with evidence of both efficacy and effectiveness. This trial evaluated the efficacy of this prevention program with Brazilian girls, as no published study has tested whether this intervention is culturally sensitive and efficacious with Latin-American adolescents.
\end{abstract}

Methods: Female students were allocated to a dissonance-based intervention $(n=40)$ or assessment-only $(n=22)$ condition. The intervention was a dissonance-based program, consisted of four group sessions aimed to reduce thin-ideal internalization. The sessions included verbal, written, and behavioral exercises. The intervention group was evaluated at pretest and posttest; assessment-only controls completed measures at parallel times.

Results: Compared to assessment-only controls, intervention participants showed a significantly greater reduction in body dissatisfaction, sociocultural influence of the media, depressive symptoms, negative affect, as well as significantly greater increases in body appreciation. There were no significant effects for disordered eating attitudes and eating disorder symptoms.

Conclusions: These results suggest that this dissonance-based eating disorder prevention program was culturally sensitive, or at least culturally adaptive, and efficacious with Brazilian female adolescents. Indeed, the average effect size was slightly larger than has been observed in the large efficacy trial of this prevention program and in recent meta-analytic reviews.

Trial registration: RBR-7prdf2. Registered 13 August 2018 (retrospectively registered).

Keywords: Eating disorder, Prevention, Dissonance, Body dissatisfaction

\section{Background}

Eating disorders (ED) affect 15\% of females and they are marked by chronicity, relapse, distress, functional impairment, and increased risk for future obesity, depression, suicide attempts, and mortality (Allen, Byrne, Oddy, \& Crosby, 2013). Although there are no data about the prevalence of ED in Brazil, it has been established that its incidence has increased in recent years (Nunes, 2006). Researchers have argued that this

\footnotetext{
* Correspondence: ana.amaral@ifsudestemg.edu.br

${ }^{1}$ Federal Institute of Education, Science and Technology of Southern of Minas Gerais, 204 Monsenhor José Augusto, São José, Barbacena 36205-018, Brazil

Full list of author information is available at the end of the article
}

increase could be because of greater understanding of this subject and the more accurate diagnosis of these disorders (Nunes, 2006; Prisco, Araujo, Almeida, \& Santos, 2013). According to Smink, van Hoeken, and Hoek (2012), there has been an increase in the high risk-group of 15-19-year-old girls, who meet diagnostic criteria for subclinical conditions of ED.

As $80-90 \%$ of those with eating disorders do not receive treatment (Swanson, Crow, Le Grange, Swendsen, \& Merikangas, 2011), a public health priority is to broadly implement effective eating disorder prevention programs focused in eating disorders risk factors, such as body dissatisfaction. 
Many studies have revealed elevated body dissatisfaction among Brazilian female adolescents (e.g., Alves, Vasconcelos, Calvo, \& Neves, 2008; Laus, Miranda, Almeida, Costa, \& Ferreira, 2012; Martins \& Petroski, 2015; Scherer, Martins, Pelegrini, Matheus, \& Petroski, 2010; Vale, Kerr, \& Bosi, 2011). Amaral and Ferreira (2017), in their 1-year follow-up, concluded that the media influence was the most powerful predictor of body dissatisfaction among Brazilian girls, which in turn, predicted risky eating attitudes. Similarly, other studies conducted in Brazil have found that media contributes to body image disturbances, particularly among adolescent girls and young women (Alvarenga, Dunker, Philippi, \& Scagliusi, 2010; Fortes, Amaral, Almeida, \& Ferreira, 2013).

One eating disorder prevention program with a broad evidence base is the Body Project (BP; Stice, Mazotti, Weibel, \& Agras, 2000). This intervention is based on cognitive-dissonance theory, proposed by Festinger (1957), that suggest that people are motivated to maintain consistency between their behaviors and attitudes, and that when an individual engages in a behavior that is inconsistent with an attitude, they experience psychological discomfort that causes them to align their attitudes with their behavior. In this group-based eating disorder prevention program, adolescent girls voluntarily critique the thin beauty ideal in verbal, written, and behavioral exercises, which theoretically generates cognitive dissonance that prompts them to reduce their subscription to this unrealistic ideal because people are motivated to align their attitudes with their publically displayed behaviors.

$\mathrm{BP}$ is a four-session intervention wherein participants verbally generate costs associated with pursuing the thin ideal in response to Socratic questions, complete roleplays in which they talk facilitators out of pursuing this ideal, write a letter to a younger self on how to avoid body image concerns, and engage in acts of body activism that challenge this ideal (intervention script can be found at www.bodyprojectsupport.org). This intervention is based on The Dual Pathway Model that hypothesizes that thin-ideal internalization increases risk for body dissatisfaction, which in turn increases risk for subsequent dieting and negative affect, which increases risk for ED onset (Stice, 2001). Stice, Marti, Rohde, and Shaw (2011) confirmed that a decrease in thin-ideal internalization mediated the effects of the BP on body dissatisfaction, and further than a reduction of body dissatisfaction mediated the decline in eating disorders symptoms.

The BP is one of the few prevention programs to significantly decrease onset of eating disorders over follow-up in multiple trials, outperform active alternative prevention programs, and to produce effects in trials conducted by independent research teams in North America and Europe (e.g., Becker, Smith, \& Ciao, 2005; Halliwell, Jarman, McNamara, Risdon, \& Jankowski, 2015; Matusek, Wendt, \& Wiseman, 2004; Serdar et al., 2014; Stice, Marti, Spoor, Presnell, \& Shaw, 2008; Stice, Rohde, Shaw, \& Gau, 2011). These trials have demonstrated that this cognitivedissonance intervention has produced greater reductions in eating disorder risk factors (such as thin-ideal internalization, body dissatisfaction, dieting, negative affect) and eating disorder symptoms in adolescent girls and young women with body image concerns relative to assessmentonly control conditions, and often relative to alternative interventions.

The meta-analytic review conducted by Le, Barendregt, Hay, and Mihalopoulos (2017) noted out that cognitive-dissonance interventions were effective in reducing risk factors (e.g., body dissatisfaction, thin-ideal internalization, negative affect, and dieting) and symptoms of eating disorders for late adolescents and young women. Moreover, the BP has produced effects when implemented selectively with women who have body image concerns, as well as when implemented universally to women and adolescents who were not screened for body image concerns or when implemented in an indicated fashion with women who have subclinical eating pathology (Stice, Shaw, \& Marti, 2007).

It is essential to evaluate the efficacy of eating disorder prevention among different ethnic groups, in order to determine whether prevention programs need to be modified to fit the particular needs of different groups. Although there is some evidence that the BP is similarly effective for Asian American, African American, Hispanic, and European American females (Rodriguez, Marchand, Ng, \& Stice, 2008; Stice, Marti, \& Cheng, 2014), no randomized trials have evaluated the efficacy of the BP among young women from other cultures. Thus, the objective of the present study was to evaluate the efficacy of the BP for Latin-American girls in Brazil. We hypothesize that the BP will produce significantly greater reductions in body-image dissatisfaction, sociocultural influences by the media, disordered eating attitudes and behaviors, eating disorders symptoms, negative affect, and increase body appreciation in the intervention group than changes observed in assessmentonly controls.

\section{Methods}

\section{Participants and procedure}

Initially, the sample size was calculated using as parameters the average effect size of the larger efficacy trial of BP from the comparison among intervention and assessment-only conditions $(d=0.56$; Stice, Shaw, Burton, \& Wade, 2006), the expected power (0.80), the significance level $(p<.05)$, and the statistical test (mixed 
repeated measures ANOVA). The minimal sample size indicated to a representative sample was 80 participants.

Recruitment was conducted via flyers and was directed to adolescent girls from the technical education integrated to the high school of the "Instituto Federal do Sudeste de Minas Gerais". This report is about girls recruited between August 2015 and March 2017. Girls with body image concerns were included in this study (accessed by the direct question "Do you have body image concerns?"). They also should not met criteria for eating disorders (accessed by the direct question "Have you ever been diagnosed with some kind of eating disorder (e.g., anorexia and bulimia)?"). Therefore, this represents a selective prevention program.

One hundred forty one adolescent females $(M$ age $=$ $16.25, S D=1.4$ ) accepted the invitation to enroll the trial. Girls that voluntarily accept take part in the study were randomized to the intervention or assessment-only condition through the website www.randomization.com. In total, 79 participants were assigned to the $\mathrm{BP}$ condition and 62 participants were assigned to an assessment-only condition.
The final sample in the posttest was composed by 40 participants in the intervention group, that completed the four-session protocol, and 22 assessment-only controls, who answered the questionnaire in both pre- and posttest (see Fig. Fig. 1 for a participant flowchart).

\section{Intervention}

The BP consisted of four weekly 1-h group and each intervention group included five to eight participants. Facilitators delivered the intervention using a scripted manual. Participants completed assessments at pretest and posttest and the assessment-only controls completed measures at parallel times. All the measures were selfreported with no limit of time to answer the questionnaires.

The scripted intervention manual was translated into Portuguese, aiming to be as faithful as possible to the original (see Table 1 for the script of each session and visit www.bodyprojectsupport.org for the Portuguese translation of the intervention script). The sessions took place at the school's premises, after school hours,

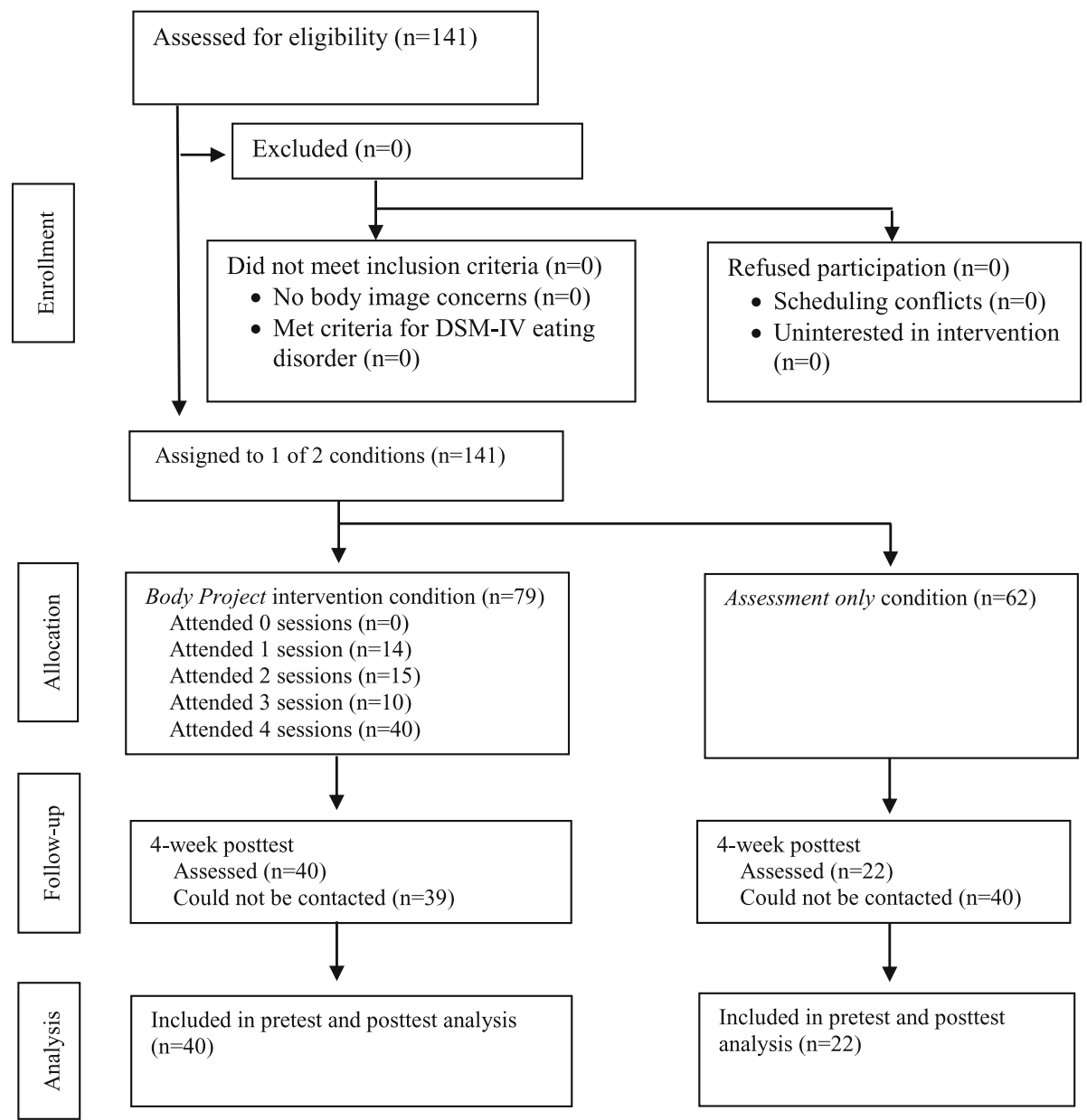

Fig. 1 Participant flow throughout study 
Table 1 Description of the Body Project intervention

\begin{tabular}{ll}
\hline Session & Description \\
\hline 1 & In session 1, participants collectively define the thin ideal, \\
discuss costs of pursuing this ideal, and are assigned home \\
exercises (e.g., write an essay about the costs associated \\
with pursuing the thin ideal).
\end{tabular}

according the availability of the participants. The intervention was implemented by researchers trained in the intervention protocol. As done in other trials, we underscored the voluntary nature of participation and increased accountability (e.g., by videotaping sessions) to increase dissonance induction. This is justified because the voluntary engagement in counter-attitudinal activities, such as exploring costs of pursuing the thin ideal, produces greater attitudinal change (Green, Scott, Diyankova, Gasser, \& Pederson, 2005; Stice, Shaw, Becker, \& Rohde, 2008).

Procedures were approved by the Research Ethics Committee on Human Beings of "Universidade Federal de Juiz de Fora" (n 228.386).

\section{Measures}

Primary outcomes

Body dissatisfaction Body weight and shape concerns were assessed with the 34-item Body Shape Questionnaire (BSQ). Scores ranged from 34 to 204, wherein the higher the score, the greater the body dissatisfaction. This scale has shown internal consistency $(\alpha=.96)$ and test-retest reliability $(r=.91)$ for Brazilian adolescents (Conti, Cordás, \& Latorre, 2009). According to the final scores, the girls were classified as having no dissatisfaction (scores of less than 80), with slight dissatisfaction (scores between 80 and 110), moderate dissatisfaction (scores between 111 and 140), or serious dissatisfaction (scores higher than 140). The internal consistency of BSQ for the present study sample, as evaluated using Cronbach's alpha, was .95 at pretest and .93 at posttest.

Sociocultural influences The 30-item Sociocultural Attitudes Towards Appearance Questionnaire-3 (SATAQ3) assessed the influence of the media on body image, including thin-ideal internalization, pressures to be thin, and the media as source of information about appearance. The final score was calculated by the sum of the responses, ranged from 30 to 150, and the score proportionally represented the influence of sociocultural aspects on body image. This scale has shown internal consistency $(\alpha>.91), \quad 2$-week test-retest reliability $(r=.86)$, and factorial structure among Brazilian adolescents (Amaral, Conti, Filgueiras, \& Ferreira, 2015). Cronbach's alpha in the present study sample was .94 at pretest and .90 at posttest.

Disordered eating attitudes and behaviors The 26item Eating Attitudes Test (EAT-26), in its version validated for Brazilian girls $(\alpha=.82$; Bighetti, Santos, Santos, \& Ribeiro, 2004), assessed disordered eating attitudes and behaviors. The total score ranges from zero to 78 points, wherein the higher the score, the higher the risk of developing an eating disorder. Scores higher than 21 show a risky eating behavior (Garner, Olmsted, Bohr, \& Garfinkel, 1982). The evaluation of the internal consistency of this scale for the present study sample was .79 at pretest and .71 at posttest.

Eating disorders symptoms The Eating Disorder Diagnostic Scale (EDDS; Stice, Fisher, \& Martinez, 2004) was used to evaluate symptoms of eating disorders. EDSS is composed by 23 items and the final score is calculated by the sum of the responses. Cronbach's alpha value for the present study sample was .83 at pretest and .79 at posttest and its association with EAT-26 was .60 $(p<.001)$.

\section{Secondary outcomes}

Depressive symptoms The 20-item version of the Children Depression Inventory (CDI) was used to evaluate the presence and severity of depressive symptoms. The total score ranges from zero to 54 points, and the higher the score, the greater the presence of depressive symptoms. This scale has shown internal consistency $(\alpha=.81)$ and 1-factor structure among Brazilian adolescents between 7 and 17 years old (Wathier, Dell'Aglio, \& Bandeira, 2008). The internal consistency of this scale for the present study sample was .90 at pretest and .71 at posttest.

Body appreciation Body appreciation was evaluated through the 13-item Body Appreciation Scale (BAS). The final score was calculated by the sum of the responses and ranged from 13 to 65 . For the BAS, the higher the total score, the higher the own body appreciation. The version used in the present study was the one translated into Portuguese and has shown internal consistency $(\alpha=.90$; Caetano, 2011). Recently, the psychometric properties of this scale were provided for 
young Brazilian adolescents (Moreira, Lorenzato, Neufeld, \& Almeida, 2018). The internal consistency of this scale for the present study sample was .90 at pretest and .91 at posttest.

Negative affect The 15 items related to negative emotional states (e.g., sad, ashamed, angry, and nervous) of the Positive Affect and Negative Affect Scale (PANAS; Laurent et al., 1999) was used to evaluate the negative affect. The final score was the average of items responses. This scale has shown adequate internal consistency (.95 at pretest and .93 at posttest) and was significantly associated to the scores of CDI $(r=.62 ; p<.001)$.

Both scales EDDS and PANAS are part of the Body Project Protocol. These scales are not validated for Brazilian adolescent girls. Thus, they were translated and back-translated and showed adequate internal consistency and significant correlations with measures of similar constructs, as described before. Since there are no validated measures to evaluate these outcomes, we included them in order to provide comparative results with others trials.

\section{Data analysis}

Initially, a descriptive analysis of all variables was carried out, including mean and standard deviation values. Due to the distribution abnormality and sample size, nonparametric statistics were used. The preliminary analysis aimed to evaluate differences in the variables between the intervention group and the assessment-only controls at pretest, using the independent samples MannWhitney $U$ test (attrition analyze).

In order to verify if the participants in the intervention condition had shown significantly greater reductions than the assessment-only participants, mixed repeated measures ANOVA was carried out for each outcome. We consider the allocation (intervention and assessment-only) as the between-subjects factor and the time (pre- and posttest) as the within-subjects factor. For the outcomes with significant group $\times$ time interactions, we made the post-hoc analysis, using the independent samples Mann-Whitney $U$ test to verify differences between the groups in the posttest and the related samples Wilcoxon signed rank test to evaluate changes in the outcome from pre- to posttest. In addition, the effect size (Cohen's $d$ ) was calculated and classified according to Cohen (1988): no effect (0-0.19), small (0.20-0.49), intermediate (0.50-0.79), large $(0.80-$ $1.29)$, and very large $(>1.30)$.

The analyses were performed in the IBM SPSS (Statistical Package for the Social Sciences) program for Windows, version 21.0, adopting the significance level of 95\% $(p<.05)$.
Moreover, the post-hoc tests for achieved power for each of outcomes were calculated, as well as for the average effect-size, using as parameters the observed effect-size and the final sample size. This analysis was performed using the GPower software, using a $p=.05$.

\section{Results}

\section{Preliminary analysis}

With regard to attendance, a total of 50,6\% of intervention participants attended all four sessions (and completed the posttest assessment), $12.7 \%$ attended three sessions, $19 \%$ attended two sessions, and $17.7 \%$ attended one session. Among the assessment-only controls, the $35.5 \%$ completed the posttest assessment.

Descriptive statistics (means and standard deviations) for each outcome are presented in Table 2. Girls in the intervention group were classified as no dissatisfied (scores smaller than 80) and the assessment-only controls showed slight dissatisfaction (scores between 80 and 110) evaluated by the BSQ. Moreover, participants of both groups did not showed disordered eating attitudes and behaviors (scores smaller than 21), according to the EAT-26. There were no differences among participants in the two conditions in outcomes at pretest (see Table 2).

\section{Comparison and differences between groups on pre-post scores in primary outcomes}

There was a significant group $\times$ time interaction for preto post change for two of the primary outcomes (see Table 3): body dissatisfaction (BSQ: $F[1,50]=13.99$. $p<.001)$ and sociocultural influence of the media (SATAQ-3: $F[1,49]=14.40, p<.001)$. In both cases, the interaction reflected a greater pre- to post reduction in the BP group relative to the assessment-only controls, whose scores remained stable or increased from the preto posttest. The group $\times$ time interaction did not reach significance for eating attitudes and behaviors (EAT-26: $p=.08$ ) or eating disorders symptoms (EDDS: $p=.06$ ).

\section{Comparison and differences between groups on pre-post scores in secondary outcomes}

There was a significant group $\times$ time interaction for preto post change for all the secondary outcomes: depressive symptoms (CDI: $F[1,48]=8.24, p=.006$ ), negative affect (PANAS: $F[1,48]=6.64, p=.013$ ), and body appreciation (BAS: $F[1,56]=9.07, p=.004$ ), with BP participants showing greater reductions on depressive symptoms and negative affect and greater increases on body appreciation than assessment-only participants.

The observed power for each of the outcomes evaluated, taking into account the final sample size $(n=62)$, are presented in Table 3. Considering the average effect size $(d=0.74)$, the power of the study was 0.99 . 
Table 2 Means and standard deviations for the intervention participants and assessment-only group on the outcome variables

\begin{tabular}{|c|c|c|c|}
\hline Variables & & $\begin{array}{l}\text { Pretest } \\
M(S D)\end{array}$ & $\begin{array}{l}\text { Posttest } \\
M(S D)\end{array}$ \\
\hline \multirow[t]{2}{*}{ Body dissatisfaction (BSQ) } & Body Project & $77.49(30.89)$ & $55.81(21.12)^{*}$ \\
\hline & Assessment-only & 80.69 (36.49) & $92.72(43.52)^{\dagger}$ \\
\hline \multirow[t]{2}{*}{ Sociocultural influences (SATAQ-3) } & Body Project & $75.76(24.65)$ & $59.11(19.71)^{*}$ \\
\hline & Assessment-only & $82.78(23.58)$ & $82.84(27.96)^{\dagger}$ \\
\hline \multirow[t]{2}{*}{ Eating attitudes (EAT-26) } & Body Project & $11.76(9.02)$ & $7.85(6.76)^{* *}$ \\
\hline & Assessment-only & $14.33(15.62)$ & $17.47(12.32)$ \\
\hline \multirow[t]{2}{*}{ Eating disorders symptoms (EDDS) } & Body Project & $10.32(10.57)$ & $7.03(9.73)^{*}$ \\
\hline & Assessment-only & $11.87(11.87)$ & $12.00(10.64)$ \\
\hline \multirow[t]{2}{*}{ Depression symptoms (CDI) } & Body Project & $9.70(7.97)$ & $6.32(4.67)^{*}$ \\
\hline & Assessment-only & $11.86(10.66)$ & $13.44(15.09)^{\dagger}$ \\
\hline \multirow[t]{2}{*}{ Negative affect (PANAS) } & Body Project & $2.45(1.26)$ & $1.81(0.66)^{*}$ \\
\hline & Assessment-only & $2.23(0.84)$ & $2.34(1.51)^{\dagger}$ \\
\hline \multirow[t]{2}{*}{ Body appreciation (BAS) } & Body Project & $44.01(10.56)$ & $53.26(8.98)^{*}$ \\
\hline & Assessment-only & $45.73(18.95)$ & $41.40(10.37)^{\dagger}$ \\
\hline
\end{tabular}

${ }^{*} p<.001$ and ${ }^{* *} p<.05$ between pre- to posttest from related samples Wilcoxon signed rank test. ${ }^{\top} p<.05$ between assessment-only and intervention from independent samples Mann-Whitney $U$ test

\section{Discussion}

This trial evaluated the efficacy of a dissonance-based eating disorder prevention program among LatinAmerican adolescent females in Brazil. This study makes a novel contribution because it is important to determine whether interventions created in different cultural backgrounds are effective in different cultures.

Table 3 Group $\times$ time interactions on the outcomes variables and effect sizes (Cohen's $d$ )

\begin{tabular}{|c|c|c|c|c|c|}
\hline \multirow[t]{2}{*}{ Variables } & \multicolumn{5}{|c|}{ Group $\times$ time interaction ${ }^{a}$} \\
\hline & $\bar{F}$ & $p$ & $d$ & Effect size ${ }^{b}$ & Power' $^{c}$ \\
\hline \multicolumn{6}{|c|}{ Body dissatisfaction } \\
\hline BSQ & 14.00 & .000 & 0.92 & Large & 0.99 \\
\hline \multicolumn{6}{|c|}{ Sociocultural influences } \\
\hline SATAQ-3 & 14.40 & .000 & 0.96 & Large & 1.00 \\
\hline \multicolumn{6}{|c|}{ Eating attitudes } \\
\hline EAT-26 & 3.28 & .076 & 0.46 & Intermediate & 0.94 \\
\hline \multicolumn{6}{|c|}{ Eating disorders symptoms } \\
\hline EDDS & 3.83 & .056 & 0.56 & Intermediate & 0.99 \\
\hline \multicolumn{6}{|c|}{ Depressive symptoms } \\
\hline CDI & 8.24 & .006 & 0.80 & Large & 0.99 \\
\hline \multicolumn{6}{|c|}{ Negative affect } \\
\hline PANAS & 6.64 & .013 & 0.75 & Intermediate & 0.99 \\
\hline \multicolumn{6}{|c|}{ Body appreciation } \\
\hline BAS & 9.07 & .004 & 0.71 & Intermediate & 0.99 \\
\hline
\end{tabular}

Moreover, this is the first trial conducted in Brazil to evaluate an eating disorder prevention program with a strong evidence-base, as have been shown by recent meta-analytic reviews (Le et al., 2017; Stice et al., 2007).

One explanation for why the BP is similarly effective in different cultural backgrounds, and among participants of this study, is that this intervention is participant-driven, what may make it naturally culturally adapting. For example, the Socratic questions used in the sessions allowed Brazilian girls to describe and criticize the body-ideal promoted in Brazil. Furthermore, research suggests that cultural pressure for thinness also appears to influence body image in young women in Brazil and that the prevalence of eating disorders is similar of which that has been noted in other countries (Fortes et al., 2013; Zordão et al., 2015).

The BP reduced body dissatisfaction, replicating effects from the large efficacy trial conducted in North America (Stice et al., 2006), as well as confirming the findings of recent meta-analytic reviews about the effects of dissonance-based intervention on body dissatisfaction (Le et al., 2017; Stice et al., 2007; Watson et al., 2016). Perez, Becker, and Ramirez (2010), using BSQ as measure of body dissatisfaction, also reported a reduction on levels of this outcome in young women of cognitivedissonance intervention group. As body dissatisfaction is one of the most robust ED risk factors and significantly more common than clinical ED, interventions that are able to reduce body dissatisfaction should be encouraged and compose the public health efforts (Becker \& Stice, 2017).

The BP also significantly reduced the influence of the media among the adolescent girls in the intervention 
group, relative to the assessment-only controls, which corresponded to a large effect $(d=.96)$. This may be considered one of the main outcomes when evaluating the efficacy of this program since the reduction of the thin-ideal internalization, also accessed by the SATAQ-3, was the main mediator of the effects of this intervention (Stice, Marti et al., 2011). Several efficacy trials have found that BP produced greater reduction on thin-ideal internalization in adolescent girls and young women relative to assessment-only control conditions as well as relative to alternative intervention (Stice, Chase, Stormer, \& Appel, 2001; Stice et al., 2000, 2006; Stice, Marti et al., 2008; Stice, Trost, \& Chase, 2003). These results are confirmed in the present study.

The hypothesis that BP would reduce the ED attitudes and symptoms was partially supported. Although the effects for eating disorder attitudes and behaviors (EAT26) and eating disorder symptoms (EDDS) did not reach significance, the effect sizes were medium $(d=.46$ and .56 respectively) and the power for this outcome was high (0.99). Also, the effect size for eating disorder symptoms is similar to or larger than the effect size found in trials (e.g., Stice et al., 2006; Stice, Butryn, Rohde, Shaw, \& Marti, 2013). A potential explanation for these limited effects is that participants in the intervention had already low mean disordered eating attitudes and symptoms at pretest. Divergent results were found by Becker et al. (2005), in the universal version of the BP. Using the EAT-26 as measure of disordered eating attitudes and behaviors, the results indicated the efficacy of the program on this outcome, with greater reductions of the scores in the intervention group when compared to controls. McMillan, Stice, and Rohde (2011) did observe significant reduction in ED symptoms at posttest, but this effect was not significant by 3month follow-up. The authors argued that maybe the self-reported measure are not sensitive enough to optimally measure change in ED symptoms.

Additionally, the BP significantly reduced depressive symptoms and the negative affect among participants ( $d=.80$ and .75 respectively). Stice, Rohde, Durant, Shaw, and Wade (2013), using a CDI-like measure to evaluate this outcome, observed reduction on depressive symptoms in the intervention group. In general, most trials have found that the $\mathrm{BP}$ reduces negative affect (Becker et al., 2010; Stice, Marti et al., 2008), though effect sizes are typically smaller for this outcome.

Further, the BP increased body appreciation, with girls who participated of the intervention having significant higher scores than those in the assessment-only condition $(d=.71)$. This result replicates the effects observed in a trial from the UK (Halliwell et al., 2015), in which the body appreciation increased among the adolescent girls (14 and 15 years old) in the intervention group, with effects ranging from weak to intermediate $(d=$ 0.51). This finding is important because few eating disorder prevention trials have measured positive body image (Halliwell et al., 2015; Jankowski et al., 2017). Thus, it provides evidence that dissonance-based programs, in addition to reducing pathological aspects, also promote positive attitudes toward one's body.

The interpretation of effect sizes is especially useful when comparing to other effects in the literature (Lakens, 2013). In this sense, the average effect size for the group $\times$ time interaction was $d=0.74$, which reflects a greater effect size than those observed in similar trials (Halliwell \& Diedrichs, 2014; Stice et al., 2006). For instance, in the efficacy trial of the BP (Stice et al., 2006), the average effect size was $d=0.59$.

It is important to highlight that most of the trials that have been developed to evaluate the efficacy of the BP are selective (directed to young women with body image concerns) and results from selective prevention trials may not generalize to other sampling frames, such as young girls and women without body image concerns (Stice, Marti, et al., 2011). However, the BP has also shown efficacy when implemented universally to young women who were not screened for body image concerns (Becker et al., 2005). Participants in this study were concerned with their body image. Indeed, adolescent girls are considered as a high-risk group for body dissatisfaction and have demonstrated a normative body dissatisfaction (Duarte, Ferreira, Trindade, \& Pinto-Gouveia, 2016; Littleton, 2008), which justify preventive efforts to reduce this outcome.

Despite these results, some limitations should be highlighted. First, we had a large dropout rate, which can be explained by the voluntary nature of the participation. Despite this, post-hoc tests pointed to a power of 0.99 , considering the final sample size $(n=62)$, indicating that this study is able to identify real effects. Second, the assessment-only control condition was not a rigorous comparison condition because it did not control for demand characteristics inherent to randomized trials. But this seemed reasonable because the BP has significantly outperformed five alternative interventions in past trials, producing larger reductions in the outcomes. Third, we did not collect demographic data. However, it is important to highlight that body dissatisfaction and sociocultural influences have been observed in different socioeconomic levels as well as diverse demographic characteristics in Brazil (e.g., Laus et al., 2012). Fourth, we did not collect follow-up data. We argue that the pre- to posttest effects have been consistently reported in the literature. Also, it is difficult to keep the voluntary adhesion in long-term follow-ups in the Brazilian context, since it is not permitted to reimburse participants for completing assessments. However, given that the BP 
has produced significant effects through 3-year followup in multiple trials mitigates this concern somewhat. Finally, we did not use a more conservative $p$ value to reduce the odds of chance findings because we were worried about missing true effects due to our relatively small sample size. We believe that replication is the most critical test of whether effects are reliable and the literature suggests that the BP does produce reliable effects across trials. A review of the literature indicates that 59 out of the 62 tests of the intervention effects for the core outcomes (thin-ideal internalization, body dissatisfaction, dieting, negative affect, and eating disorder symptoms) from pretest to posttest were significant in the 11 trials that Stice and his colleagues have conducted before the present trial (95\%) which is reassuring because one would have expected only 3.1 out of these 62 effects to have emerged by chance (5\%). Further, 34 out of the 47 tests of the intervention effects for the core outcomes were significant in 11 trials of the BP conducted by independent teams $(72 \%)$, which is likewise much higher than the 2.4 out of 47 effects (5\%) that would be expected based on chance. Thus, it seems highly unlikely that the effects reported herein are chance findings.

\section{Conclusions}

In conclusion, the current findings support the usefulness of cognitive dissonance-based programs in the reduction of risk factors related to body dissatisfaction and to eating disorders and suggest that the participant-driven nature of the group discussions make it naturally culturally adapting. Advances such as the inclusion of measurements of body appreciation in the intervention are noteworthy. The novel evidence that the BP was efficacious for LatinAmerican adolescent females in Brazil generally extends evidence that this prevention program was similarly efficacious for various ethnic groups in North America and Europe (Halliwell et al., 2015; Rodriguez et al., 2008; Stice et al., 2014).

Results from the present study also provide directions for future research on the BP. It is fundamental to test the efficacy of the proposed program with a larger sample in Brazilian context and other unique cultures, using both the assessment-only control group and an active alternative comparison intervention and longer followups. After confirming its efficacy, it is important to conduct studies aiming to evaluate the effects under realworld conditions, to confirm the effectiveness of this program. Last, it will be vital to evaluate how best to effectively implement this prevention program on a broadscale basis, with the hope of reducing the incidence of eating disorders worldwide.

\section{Abbreviations}

BAS: Body Appreciation Scale; BP: Body Project; BSQ: Body Shape

Questionnaire; CDI: Children's Depression Inventory; EAT-26: Eating Attitudes Test-26; ED: Eating disorders; EDDS: Eating Disorder Diagnostic Scale;

PANAS: Positive Affect and Negative Affect Scale; SATAQ-3: Sociocultural Attitudes Toward Appearance Questionnaire-3; SPSS: Statistical Package Social Sciences software

\section{Acknowledgements}

We would like to thank Tassiana Hudson, Juliana Lourenço, Leila Carvalho, Lívia Melo, Alcimara Araújo, Alessandra Ana, and Aline Medeiros for the support on the recruitment of participants and on the application of the intervention protocol.

\section{Special permissions}

The scales used in this study are in the public domain and permission was not necessary. The adaptation of the intervention protocol was made with the author's permission and the Brazilian version is available on the Body Project support website (http://www.bodyprojectsupport.org/resources/ materials)

\section{Authors' contributions}

ACSA designed and executed the study, helped with data analysis, and wrote the article. ES guided the execution of the study, and helped with the writing of the article. MEC guided the execution of the study and helped with the writing of the article. All authors read and approved the final manuscript.

\section{Funding}

This study was funded by Conselho Nacional de Desenvolvimento Científico e Tecnológico (CNPq) and by Instituto Federal de Educação, Ciência e Tecnologia do Sudeste de Minas Gerais (IF Sudeste MG) awarded to Ana Carolina S. Amaral. (Public notice 04/2016 and 01/2017 from IF Sudeste MG/ CNPq - academic scholarships; and Public notice 9/2018 from IF Sudeste MG - researcher scholarship).

\section{Availability of data and materials}

The datasets used and/or analyzed during the current study are available from the corresponding author on reasonable request.

\section{Ethics approval and consent to participate}

Procedures were approved by the Research Ethics Committee on Human Beings of "Universidade Federal de Juiz de Fora" (n 228.386). The trial registration number in "Registro Brasileiro de Ensaios Clínicos" is RBR-7prdf2. All the participants' parents assigned the Consent form and the volunteers assign the Agreement form.

Consent for publication

Not applicable.

\section{Competing interests}

The authors declare that they have no competing interests.

\section{Author details}

${ }^{1}$ Federal Institute of Education, Science and Technology of Southern of Minas Gerais, 204 Monsenhor José Augusto, São José, Barbacena 36205-018, Brazil. ${ }^{2}$ Oregon Research Institute, 1776 Millrace Drive, Eugene, OR 97403, USA. ${ }^{3}$ Federal University of Juiz de Fora, Campus Martelos, Juiz de Fora 36036-330, Brazil.

Received: 1 September 2018 Accepted: 21 May 2019

Published online: 17 June 2019

\section{References}

Allen, K. L., Byrne, S. M., Oddy, W. H., \& Crosby, R. D. (2013). DSM-IV-TR and DSM-5 eating disorders in adolescents: Prevalence, stability, and psychosocial correlates in a population-based sample of male and female adolescents. Journal of Abnormal Psychology, 122(3), 720-732. https://doi.org/10.1037/ a0034004.

Alvarenga, M. S., Dunker, K. L. L., Philippi, S. T., \& Scagliusi, F. B. (2010). Influência da mídia em universitárias brasileiras de diferentes regiões. Jornal Brasileiro de Psiquiatria, 59(2), 111-118. https://doi.org/10.1590/S0047-20852010000200006. 
Alves, E., Vasconcelos, F. A. G., Calvo, M. C. M., \& Neves, J. (2008). Prevalência de sintomas de anorexia nervosa e insatisfação com a Imagem Corporal em adolescentes do sexo feminino do município de Florianópolis, Santa Catarina, Brasil. Cadernos de Saúde Pública, 24, 503-512. https://doi.org/10. 1590/s0102-311×2008000300004.

Amaral, A. C. S., Conti, M. A., Filgueiras, J. F. F., \& Ferreira, M. E. C. (2015). Qualidades Psicométricas do Questionário de Atitudes Socioculturais em relação à aparência-3 (SATAQ-3) para adolescentes. Psicologia: Teoria e Pesquisa, 31(4), 471-479. https://doi.org/10.1590/010237722015042419471479.

Amaral, A. C. S., \& Ferreira, M. E. C. (2017). Body dissatisfaction and associated factors among Brazilian adolescents: A longitudinal study. Body Image, 22, 32-38. https://doi.org/10.1016/j.bodyim.2017.04.006

Becker, C. B., Smith, L. M., \& Ciao, A. C. (2005). Reducing eating disorder risk factors in sorority members: A randomized trial. Behavior Therapy, 36, 245253. https://doi.org/10.1037/0022-0167.53.4.550.

Becker, C. B., \& Stice, E. (2017). From efficacy to effectiveness to broad implementation: Evolution of the body project. Journal of Consulting and Clinical Psychology, 85(8), 767-778. https://doi.org/10.1037/ccp0000204.

Becker, C. B., Wilson, C., Williams, A., Kelly, M., McDaniel, L., \& Elmquist, J. (2010). Peer-facilitated cognitive dissonance versus healthy weight eating disorders prevention: A randomized comparison. Body Image, 7, 280-288. https://doi. org/10.1016/j.bodyim.2010.06.004.

Bighetti, F., Santos, C. B., Santos, J. E., \& Ribeiro, R. P. P. (2004). Tradução e avaliação do Eating Attitudes Test em adolescentes do sexo feminino de Ribeirão Preto, São Paulo. Jornal Brasileiro de Psiquiatria, 53, 339-346.

Caetano, A. S. (2011). Translation, cultural and factorial structure of body shape questionnaire, body esteem scale and body appreciation scale among middleaged women. São Paulo: Doctoral thesis, University of Campinas, Campinas Retrieved from http://repositorio.unicamp.br/jspui/handle/REPOSIP/275031.

Cohen, J. (1988). Statistical power analysis for the behavioral sciences, (2nd ed., ). Hillsdale: Lawrence Erlbaum Associates.

Conti, M. A., Cordás, T. A., \& Latorre, M. R. D. O. (2009). A study of the validity and reliability of the Brazilian version of the Body Shape Questionnaire (BSQ) among adolescents. Revista Brasileira de Saúde Materno Infantil, 9, 331-338. https://doi.org/10.1590/S1519-38292009000300012.

Duarte, C., Ferreira, C., Trindade, I. A., \& Pinto-Gouveia, J. (2016). Normative body dissatisfaction and eating psychopathology in teenage girls: The impact of inflexible eating rules. Eating and Weight Disorders, 21(1), 41-48. https://doi. org/10.1007/s40519-015-0212-1.

Festinger, L. (1957). A theory of cognitive dissonance. Stanford: Stanford University Press.

Fortes, L. S., Amaral, A. C. S., Almeida, S. S., \& Ferreira, M. E. C. (2013). Internalização do Ideal de Magreza e Insatisfação com a Imagem Corporal em Meninas Adolescentes. Psico, 44, 432-438.

Garner, D. M., Olmsted, M. P., Bohr, Y., \& Garfinkel, P. A. (1982). The eating attitudes test: Psychometric features and clinical correlations. Psychology Medicine, 12, 871-878. https://doi.org/10.1017/S0033291700049163.

Green, M., Scott, N., Diyankova, I., Gasser, C., \& Pederson, E. (2005). Eating disorder prevention: An experimental comparison of high-level dissonance, low level dissonance, and no-treatment control. Eating Disorders, 13, 157-169. https:// doi.org/10.1080/10640260590918955.

Halliwell, E., \& Diedrichs, P. (2014). Brief report: Testing a dissonance body image intervention among young girls. Healthy Psychology, 33, 201-204. https://doi. org/10.1037/a0032585.

Halliwell, E., Jarman, H., McNamara, A., Risdon, H., \& Jankowski, G. (2015). Dissemination of evidence-based body image interventions: A pilot study into the effectiveness of using undergraduate students as interventionists in secondary schools. Body Image, 14, 1-4. https://doi.org/10.1016/j.bodyim. 2015.02.002.

Jankowski, G. S., Diedrichs, P. C., Atkinson, M. J., Fawkner, H., Gough, B., \& Halliwell, E. (2017). A pilot controlled trial of a cognitive dissonance-based body dissatisfaction intervention with young British men. Body Image, 23, 93102. https://doi.org/10.1016/j.bodyim.2017.08.006.

Lakens, D. (2013). Calculating and reporting effect sizes to facilitate cumulative science: A practical primer for $t$-tests and ANOVAs. Frontiers in Psychology, 4 , 863. https://doi.org/10.3389/fpsyg.2013.00863.

Laurent, J., Catanzaro, S. J., Joiner Jr., T. E., Rudolph, K. D., Potter, K. I., Lambert, S., .. Gathright, T. (1999). A measure of positive and negative affect for children: Scale development and preliminary validation. Psychological Assessment, 11, 326-338. https://doi.org/10.1037/1040-3590.11.3.326.
Laus, M. F., Miranda, V. P., Almeida, S. S., Costa, T. M. B., \& Ferreira, M. E. C. (2012) Geographic location, sex and nutritional status play an important role in body image concerns among Brazilian adolescents. Journal of Health Psychology, 17, 311-312. https://doi.org/10.1177/1359105311434755.

Le, L. K. D., Barendregt, J. J., Hay, P., \& Mihalopoulos, C. (2017). Prevention of eating disorders: A systematic review and meta-analysis. Clinical Psychology Review, 53, 46-58. https://doi.org/10.1016/j.cpr.2017.02.001

Littleton, H. (2008). Body image dissatisfaction: Normative discontent? Sex Roles, 59(3), 292-293. https://doi.org/10.1007/s11199-008-9399-1.

Martins, C. R., \& Petroski, E. L. (2015). Insatisfação com a imagem corporal em adolescentes do sexo feminino de uma cidade de pequeno porte: prevalência e correlações. Motricidade, 11(2), 94-106. https://doi.org/10.6063/ motricidade. 3670

Matusek, J. A., Wendt, S. J., \& Wiseman, C. V. (2004). Dissonance thin-ideal and didactic healthy behavior eating disorder prevention programs: Results from a controlled trial. International Journal of Eating Disorders, 36, 376-388. https://doi.org/10.1002/eat.20059.

McMillan, W., Stice, E., \& Rohde, P. (2011). High- and low-level dissonance-based eating disorder prevention programs with young women with body image concerns: An experimental trial. Journal of Consulting and Clinical Psychology, 79(1), 129-134. https://doi.org/10.1037/a0022143.

Moreira, G. S. X., Lorenzato, L., Neufeld, C. B., \&. Almeida, S. S. (2018). Brazilian version of the body appreciation scale (BAS) for young adolescents. The Spanish Journal of Psychology, 21. e21.doi: https://doi.org/10.1017/sjp.2018.20.

Nunes, M. A. (2006). Epidemiologia dos transtornos alimentares. In: M. A. Nunes (Org.). Transtornos alimentares e obesidade. (pp. 51-57). Porto Alegre: Artmed.

Perez, M., Becker, C. B., \& Ramirez, A. (2010). Transportability of an empirically supported dissonance-based prevention program for eating disorders. Body Image, 7, 179-186. https://doi.org/10.1016/j.bodyim.2010.02.006.

Prisco, A. P. K., Araujo, T. M., Almeida, M. M. G., \& Santos, K. O. B. (2013) Prevalência de transtornos alimentares em trabalhadores urbanos de município do Nordeste do Brasil. Ciência \& Saúde Coletiva, 18(4), 1109-1118. https://doi.org/10.1590/S1413-81232013000400024.

Rodriguez, R., Marchand, E., Ng, J., \& Stice, E. (2008). Effects of a cognitive dissonance-based eating disorder prevention program are similar for Asian American, Hispanic, and white participants. International Journal of Eating Disorders, 41(7), 618-625. https://doi.org/10.1002/eat.20532.

Scherer, F. C., Martins, C. R., Pelegrini, A., Matheus, S. C., \& Petroski, E. L. (2010). Imagem corporal em adolescentes: associação com a maturação sexual e sintomas de transtornos alimentares. Jornal Brasileiro de Psiquiatria, 59, 198202. https://doi.org/10.1590/S0047-20852010000300005.

Serdar, K., Kelly, N., Palmberg, A., Lydecker, J., Thornton, L., Tully, C., \& Mazzeo, A. (2014). Comparing online and face-to-face dissonance-based eating disorder prevention. Eating Disorders, 22, 244-260. https://doi.org/10.1080/10640266. 2013.874824.

Smink, F. R. W., van Hoeken, D., \& Hoek, H. W. (2012). Epidemiology of eating disorders: Incidence, prevalence and mortality rates. Current Psychiatry Reports, 14, 406-414. https://doi.org/10.1007/s11920-012-0282-y.

Stice, E. (2001). A prospective test of the dual pathway model of bulimic pathology: Mediating effects of dieting and negative affect. Journal of Abnormal Psychology, 110, 124-135.

Stice, E., Butryn, M., Rohde, P., Shaw, H., \& Marti, N. (2013). An effectiveness trial of a new enhanced dissonance eating disorder prevention program among female college students. Behaviour Research and Therapy, 51, 862-871. https://doi.org/10.1016/j.brat.2013.10.003.

Stice, E., Chase, A., Stormer, S., \& Appel, A. (2001). A randomized trial of a dissonance-based eating disorder prevention program. International Journal of Eating Disorders, 29(3), 247-262.

Stice, E., Fisher, M., \& Martinez, E. (2004). Eating disorder diagnostic scale: Additional evidence of reliability and validity. Psychological Assessment, 16(1), 60-71. https://doi.org/10.1037/1040-3590.16.1.60.

Stice, E., Marti, C., Spoor, S., Presnell, K., \& Shaw, H. (2008). Dissonance and healthy weight eating disorder prevention programs: Long-term effects from a randomized efficacy trial. Journal of Consulting and Clinical Psychology, 76, 329-340. https://doi.org/10.1037/0022-006X.76.2.329.

Stice, E., Marti, C. N., \& Cheng, Z. H. (2014). Effectiveness of a dissonance-based eating disorder prevention program for ethnic groups in two randomized controlled trials. Behaviour Research and Therapy, 55, 54-64. https://doi.org/ 10.1016/j.brat.2014.02.002

Stice, E., Marti, C. N., Rohde, P., \& Shaw, H. (2011). Testing mediators hypothesized to account for the effects of a dissonance eating disorder prevention 
program over longer-term follow-up. Journal of Consulting and Clinical Psychology, 79(3), 398-405. https://doi.org/10.1037/a0023321.

Stice, E., Mazotti, L., Weibel, D., \& Agras, W. S. (2000). Dissonance prevention program decreases thin-ideal internalization, body dissatisfaction, dieting, negative affect, and bulimic symptoms: A preliminary experiment. International Journal of Eating Disorders, 27, 206-217.

Stice, E., Rohde, P., Durant, S., Shaw, H., \& Wade, E. (2013). Effectiveness of peerled dissonance-based eating disorder prevention groups: Results from two randomized pilot trials. Behaviour Research and Therapy, 51, 197-206. https:// doi.org/10.1016/j.brat.2013.01.004.

Stice, E., Rohde, P., Shaw, H., \& Gau, J. (2011). An effectiveness trial of a selected dissonance-based eating disorder prevention program for female high school students: Long-term effects. Journal of Consulting and Clinical Psychology, 79, 500-508. https://doi.org/10.1037/a0024351.

Stice, E., Shaw, H., Becker, C. B., \& Rohde, P. (2008). Dissonance-based interventions for the prevention of eating disorders: Using persuasion principles to promote health. Prevention Science, 9, 114-128. https://doi.org/ 10.1007/s11121-008-0093-x.

Stice, E., Shaw, H., Burton, E., \& Wade, E. (2006). Dissonance and healthy weight eating disorder prevention programs: A randomized efficacy trial. Journal of Consulting and Clinical Psychology, 74, 263-275. https://doi.org/10.1037/0022006X.74.2.263.

Stice, E., Shaw, H., \& Marti, N. (2007). A meta-analytic review of eating disorder prevention programs: Encouraging findings. Annual Review of Clinical Psychology, 3, 207-231. https://doi.org/10.1146/annurev.clinpsy.3.022806.091447.

Stice, E., Trost, A., \& Chase, A. (2003). Health weight control and dissonance-based eating disorder prevention programs: Results from a controlled trial. International Journal of Eating Disorders, 33(1), 10-21. https://doi.org/10.1002/ eat.10109.

Swanson, S., Crow, S., Le Grange, D., Swendsen, J., \& Merikangas, K. (2011). Prevalence and correlates of eating disorders in adolescents: Results from the national comorbidity survey replication adolescent supplement. Archives of General Psychiatry, 68, 714-723. https://doi.org/10.1001/archgenpsychiatry.2011.22.

Vale, A. M. O., Kerr, L. R. S., \& Bosi, M. L. M. (2011). Comportamentos de risco para transtornos do comportamento alimentar entre adolescentes do sexo feminino de diferentes estratos sociais do Nordeste do Brasil. Ciência \& Saúde Coletiva, 16, 121-132. https://doi.org/10.1590/S1413-81232011000100016.

Wathier, J. L., Dell'Aglio, D. D., \& Bandeira, D. R. (2008). Análise Fatorial do Inventário de Depressão Infantil (CDI) em amostra de jovens brasileiros. Avaliação Psicológica, 7, 75-84

Watson, H. J., Joyce, T., French, E., Willan, V., Kane, R. T., Tanner-Smith, E. E., et al. (2016). Prevention of eating disorders: A systematic review of randomized controlled trials. International Journal of Eating Disorders, 49, 833-862. https:// doi.org/10.1002/eat.22577.

Zordão, O. P., Barbosa, A., Parisi, T. S., Graasselli, C. S. M., Nogueira, D. A., \& Silva, R. R. (2015). Associação da imagem corporal e transtornos alimentares em adolescentes de Minas Gerais (Brasil). Nutrición clínica y dietética hospitalaria 35(2), 48-56. https://doi.org/10.12873/352pizetta.

\section{Publisher's Note}

Springer Nature remains neutral with regard to jurisdictional claims in published maps and institutional affiliations.

\section{Submit your manuscript to a SpringerOpen ${ }^{\circ}$ journal and benefit from:}

- Convenient online submission

- Rigorous peer review

- Open access: articles freely available online

- High visibility within the field

- Retaining the copyright to your article

Submit your next manuscript at $\boldsymbol{\nabla}$ springeropen.com 